\title{
PSYCHO-EMOTIONAL HEALTH OF STUDENTS DURING THE COVID-19 PANDEMIC. THE ROLE OF THE SCHOOL IN IDENTIFYING STUDENTS AT RISK
}

\author{
Sorina Irimie, Petru Sandu \\ National Institute of Public Health - Regional Center of Public Health Cluj
}

\begin{abstract}
Since the identification and recognition of the disease by the WHO, the public health emergency represented by COVID-19 has escalated and threatened the well-being of societies globally. Schools, which play a key role in the individual and collective well-being of students, face unprecedented challenges in the context of the global COVID-19 pandemic. The pandemic itself caused a great deal of concern, stress and pain, factors that can cause psycho-emotional health problems for anyone and can cause acute symptoms in people with pre-existing mental health problems. This emergency context has forced the relocation of hours in online format to support students' educational needs, adding stressful situations and additional challenges. An established method for identifying students who may have anxiety or depression is the systematic screening of the school population. It is important for the school to have an action plan once students are identified as at risk of emotional distress, in order to connect them to effective support services. Teachers, along with school psychologists and physicians, should devote time to promote mental health, reduce students' worries, and alleviate depression and anxiety. It is recommended that schools develop and promote online intervention packages to support students in managing stress, anxiety and depression related to home quarantine and the academic requirements of online education. Increased attention should be paid to students with pre-existing mental health disorders.
\end{abstract}

Key words: psycho-emotional health, students, school, COVID-19

\section{Introduction}

Since the identification and recognition of the disease by the WHO [1], the public health emergency represented by COVID-19 pandemic has escalated and globally threatened the well-being of societies. In addition to the impact on physical health, there is evidence of the current direct and indirect negative psychological impact and multiple social effects of the COVID-19 pandemic and of the future negative impact on the individuals' mental health [2].

According to a UNESCO report [3], more than 1.6 billion students have had their schools temporarily closed due to the COVID-19 pandemic, representing more than $91 \%$ of all students enrolled, leading to a worldwide rapid transition to distance learning, which has the potential to endanger the well-being of students. Recent studies have shown that isolation at home and the educational process in the online format affect the physical and mental health of young people [4]. Post-traumatic stress disorder, anger, fear, sadness, nervousness, and emotional disturbances have been described among students $[5,6]$ and a recent study in China [7] indicated that more than half of high school students suffered from depression, and almost a third of them suffered from anxiety symptoms.

* Corresponding author: Sorina Irimie, National Institute of Public Health - Regional Center of Public Health Cluj, e-mail: irimie.sorina@gmail.com

Article received: 09.04.2021, accepted: 10.04.2021, published: 12.04 .2021

Cite: Irimie S, Sandu P. Psycho-emotional health of students during the COVID-19 pandemic. The role of the school in identifying students at risk. The Journal of School and University Medicine 2021;VIII(1):31-35 


\section{The role of the school in promoting the psycho-emotional wellbeing of students}

Schools have a key role in connecting the personality development in children and young people with individual and collective wellbeing which, on the long run, will shape the values and attitudes of the society they live in. Teachers play an important role in providing learning experiences and opportunities that develop and shape the character and wellbeing of children and young people.

The need to promote the children's wellbeing is widely accepted as a moral imperative, and as a pragmatic imperative, equally worthy of prioritization. Failure to protect and promote the wellbeing of children is associated with an increased risk in a wide range of aspects later in life, ranging from impaired cognitive development to poor school performance, low skills and expectations, reducedproductivity and earnings, higher unemployment rates and increased dependence on social security, increased prevalence of antisocial behavior and involvement in crime, a higher likelihood of drug use and alcohol abuse, higher levels of births among adolescents and rising costs of health care, and an increased incidence of mental illnesses $[8,9]$.

The need for social connection is fundamental for individuals. The school provides structure and routine to the students' lives. Starting with the routine of waking up at a certain time, going to school and coming home at certain hours gives a sense of normality. For most students, school means not only academic training, but also social interaction. Through their interactions with colleagues, teachers and other school staff young people learn to interact with outer family personalities. In the courtyard, hallways and classrooms of their school, young people are exposed to a variety of cultural patterns, perspectives and ways of life that may be different from their own.

\section{School in the context of the COVID-19 pandemic}

During the COVID-19 pandemic, schools are facing unprecedented challenges. The pandemic forced online relocations to support students' educational needs. The pandemic itself has caused a lot of worry, stress and pain, factors that can cause psycho-emotional health problems for anyone and acute symptoms in people with pre-existing mental health problems. For children and adolescents with mental healthproblems, school closure meant a restriction in access to resources usually available through the school. School routine is important for young people with mental health problems. When schools are closed, students lose an anchor in their lives and their symptoms may relapse[10].

Teachers can notice and signal the existence of psycho-emotional health problems among students, but in the context of school closures and the online learning process, where teachers do not meet personally with students and when they meet they cannot read their masked faces, some of the typical indicators that teachers may use to identify students facing different difficulties may not be available. As a result, teachers may face uncertainties about students' psycho-emotional state, and identifying students who may need additional support becomes difficult - especially for anxiety and depression symptoms, which can often go undetected even in more favorable circumstances.

One of the most stressful aspects of the current situation is uncertainty. It is not known who was or will be infected, who could be a carrier spreading the virus to others without even knowing, when and how schools will reopen or what will be the longterm effects of this pandemic. Dealing with so many uncertainties increases anxiety. A certain amount of fear and worry is a normal reaction to this abnormal situation, but if a person's anxiety has an intensity that disrupts the person's ability to focus on activities, interferes with the ability to sleep at night or causes difficulties in engaging in the activities they have to perform, it is necessary to turn to professional help.

\section{Universal screening for identifying students at risk}

A validated method for identifying students who may have anxiety or depression is the systematic screening of the school population. For elementary school students, screening involves completing short questionnaires about students' emotions and behaviors in the classroom. For the middle and high school levels, screening is primarily based on questioning students about the frequency or severity of any 
emotional concerns. Teachers may also be asked to nominate students who appear to be overly anxious or sad. Students can complete questionnaires using the classic method of paper and pencil surveys or, more suitable for the online training phases, online questionnaires. School mental health professionals (e.g. school psychologists, school physicians) can use the anxiety or depression questionnaires scores to identify students at risk. Sometimes these students can beasked to complete the questionnaire again a few weeks later to determine if their mental health challenges are persistent.

In the screening process, teachers are those who know best the general behavior of their students, because they have the highest daily contact with them. As a result, they can detect subtle changes in children's mood, habits and daily practices.

Subsequently, the school psychologist may administer evaluation scales. One recommended scale is the WHO-5 questionnaire (The WHO-5 Well-Being Index), a short questionnaire consisting of 5 simple and non-invasive questions, targeting the subjective well-being of respondents. The scale has adequate validity, both as a screening tool for depression and as an outcome measure in clinical trials and has been successfully applied as a generic scale for well-being in a wide range of fields of study. A systematic review of the use of this scale [11] concluded that WHO-5 is an extremely useful tool that can be applied both in the clinical practice (e.g. to detect depression) and in research studies to assess well-being over time, or to compare well-being between groups.

The Personal Wellbeing Index scale (PWI) can also be used to assess individual well-being. This scale contains 7 satisfaction items, each corresponding to a field of life: standard of living, health, personal achievements, interpersonal relationships, personal safety, community connections and the sense of security regarding the future. These seven elements, which make up the PWI, represent the first level of deconstruction of the global question „How satisfied are you with your life as a whole?,

The Personal Wellbeing Index-for-Students scale (PWI-SC) is a version of the Personal Wellbeing Index-Adult (PWI-A; IWG 2006) [12], which has been reformulated for use in high school students, but retains the essence of the adult version. Unlike the adult scale, which includes questions about ,satisfaction”, the PWI-SC elements require respondents to indicate their level of „happiness" for each area. The adjective "happy" is supported by the fact that it is easier for school-age children to understand it [13]. Domains also use a simplified wording. For example, „How satisfied are you with the security of the future?" Is replaced by „How happy are you with what you expect to happen in the future in your life?" The PWI-SC domains are the same as in the adult scale and include the standard of living, health, live achievements, relationships, safety, community connections and the sense of security regarding the future. Each field is theoretically incorporated to represent the first level of deconstruction of the global question, „How happy are you with your life as a whole?". Preliminary work of authors in a previous study has shown that this tool for assessing the well-being of students is a valid tool. According to Cummins' studies [14], the subjective level of well-being can be used as an indicator of homeostatic defeat and the risk of depression.

Prior to the COVID-19 pandemic, it was estimated that $15-20 \%$ of students could be identified at risk for depression [15]. This percentage will certainly be higher in the present days, given the potential and multiple psycho-emotional challenges in the context of the COVID-19 pandemic.

School-level mental health professionals can provide direct support to students who are potentially at risk for emotional problems, thus contributing to the implementation of systematic screening. National education law no. 1/2011, updated and published in the Romanian Official Journal [16], stipulates that "Preschoolers, pre-university and university students from state and private schools authorized/accredited benefit from free medical, psychological and speech therapy assistance, in medical, psychological and speech therapy offices in schools or in state medical units". The law stipulates that a school psychologist is assigned a number of 800 students. Starting with the school year 2021-2022, a new paragraph (paragraph 11) entered into force, which stipulates that a post of school psychologist is assigned a minimum number of 600 students, respectively a minimum of 300 preschoolers withineducational units with legal personality. However, Romania is facing an acute crisis of school psychologists, especially in rural areas, 
although the number of students who need specialized support is increasing.

Another pressing problem is represented by the fact that in Romania, according to the data provided by the Ministry of Health [17], there are 15,497 educational units and only 2,878 school medical offices. Thus, only $18.6 \%$ of schools have a medical office. During the COVID-19 pandemic, school medical staff performed epidemiological triage to identify students with symptoms, assisted teachers and support staff in implementing prevention strategies, tracking contacts, implementing testing strategies at the school level and supported, together with the school psychologist, students, families and school staff involved in managing the stress and anxiety generated by the pandemic context.

\section{Screening is part of the prevention and support process. What happens after identification?}

It is important for the school to have an action plan to connect young people to effective support services once students are identified as at risk of emotional distress. Ideally, this would involve individual or group counseling in schools as part of a multi-level support system [18]. Alternatively, students could be referred to medical facilities that treat young people with mental health disorders.

Given the many mental health challenges that students may face during the pandemic, it is important that educators: (a) help identify students at risk through systematic screening; (b) advocate for universal screening of the school population during and after the online learning phases; (c) raise awareness of the importance of mental health screening, together with fellow teachers, school administrators and parents.

\section{Conclusions}

Depression and anxiety are serious mental health problems that contribute to psychosocial and academic dysfunctions. The COVID-19 pandemic has added new components and dimensions of stress among students as a result of social isolation, new demands imposed by the online learning, which added to the fear of infection and the potential loss of a loved one. In these circumstances, the integration of psychosocial and mental health intervention should be considered as an integral part of the online education programs.

An important role in keeping schools safe and conducting the instructional-educational processes in optimal conditions is played by the medical staff in schools and psychological offices, that can identify subjects at risk of psycho-emotional disorders, depression, anxiety and promote stress adjustment methods and, overall, a good mental health.

Teachers, along with school psychologists and physicians, should devote time to promote mental health, reducing students' worries, and alleviate depression and anxiety. It is recommended to develop and promote school based online intervention packages to support students in managing stress, anxiety and depression related to home quarantine and the academic requirements of online education. Increased attention should be paid to students with pre-existing mental health disorders.

\section{BIBLIOGRAPHY}

1.https://www.who.int/emergencies/diseases/ novel-coronavirus-2019/events-as-they-happen

2. Holmes EA, O'Connor RC, Perry VH, Tracey I, Wessely S, Arseneault L, et al. Multidisciplinary research priorities for the COVID-19 pandemic: a call for action for mental health science.Lancet Psychiatry 2020;7:547-60.doi: 10.1016/ S2215-0366(20)30168-1

3. UNESCO (2020) “COVID-19 Educational Disruption and Response”, https://en.unesco.org/covid19/educationresponse[Data from April 4, 2020].

4.Alharbi R, Alsuhaibani K, Almarshad A, Alyahya A. Depression and anxiety among high school student at Qassim Region.Journal of Family Medicine and Primary Care 2019;8(2):504.

5. Brooks SK, Webster RK, Smith LE, Woodland L, Wessely S, Greenberg N, Rubin GJ. The psychological impact of quarantine and how to reduce it: Rapid review of the evidence. The Lancet 2020; 395(10227):912-920.

6.Cao W, Fang Z, Hou G, Han M, Xu X, Dong J, Zheng J. (2020). The psychological impact of the COVID-19 epidemic on college community mental health journal 13 students in China.Psychiatry Research.https://doi.org/10.1016/jpsychres. 2020.112934

7. Zhang Z, Zhai A, Yang M, Zhang J, Zhou H, Yang C, Duan S, Zhou C. Prevalence of Depression and Anxiety Symptoms of High School Students in Shandong Province During the COVID-19 Epidemic. Front. Psychiatry 2020;11:570096. doi: 10.3389/fpsyt.2020.570096

8. Duncan G, Telle K, Ziol-Guest K, Kalil A. (2009).'Longrun Impacts of Early Childhood Poverty: Comparative evidence 
from Norwegian registry data and the U.S', PSID, paper prepared for the conference 'The Long-run Impact of Early Life Events'. Michigan: National Poverty Center, University of Michigan, March 12-13 2009.

9. Johnson R, Schoeni R (2007).'The Influence of Early-Life Events on Human Capital, Health Status, and Labor Market Outcomes over the Life Course', Working Paper Series. Berkeley, CA: Institute for Research on Labor and Employment, UC Berkeley.

10. Joyce Lee, Mental health effects of school closure during COVID-19, Lancet, vol.4, 2020, www.thelancet.com/ child-adolescent

11. Winther Topp C, Østergaard SD, Søndergaard S.WHO-5 Well-Being Index: A Systematic Review of the LiteraturePsychotherPsychosom 2015;84:167-176, https://www. karger.com/Article/Pdf/376585

12. International Wellbeing Group (2013). Personal Wellbeing Index: 5th Edition. Melbourne: Australian Centre on Quality of Life, Deakin University http://www.acqol.com.au/ instruments\#measures

13. Cummins RA, Lau ALD. (2005).Personal Wellbeing
Index-School Children (PWI-SC) (3rd ed.). Melbourne: Deakin University. Retrieved July 12, 2011 from http://www.deakin.edu. $\mathrm{au} / \mathrm{research} /$ acqol/instruments/wellbeing_index.htm.

14. Cummins RA. Subjective wellbeing, homeostatically protected mood and depression: A synthesis. Journal of Happiness Studies 2010;11:1-17.

15. Dowdy E, Furlong M, Raines TC, Bovery B, Kauffman B, Kamphaus RW, Murdock J. Enhancing school-based mental health services with a preventive and promotive approach to universal screening for complete mental health. Journal of Educational and Psychological Consultation 2015;25(2-3):178-197.

16 .https://www.edu.ro/sites/default/files/ fisiere/Legislatie/2020/LEN_actualizata_octombrie_2020.pdf

17. https://www.wall-street.ro/articol/Social/245428/ mai-putin-de-20-din-scolile-din-romania-au-cabinete-medicalescoale.html\#gref

18. Eagle JW, Dowd-Eagle SE, Snyder A, Holtzman EG. Implementing a multi-tiered system of support (MTSS): Collaboration between school psychologists and administrators to promote systems-level change. Journal of Educational and Psychological Consultation 2015;25:160-177. 